\title{
Experimental study of energy performance in low-temperature hydronic heating systems
}

\author{
Arefeh Hesaraki ${ }^{\mathrm{a}, *}$, Eleftherios Bourdakis ${ }^{\mathrm{b}}$, Adnan Ploskić ${ }^{\mathrm{a}}$, Sture Holmberg ${ }^{\mathrm{a}}$ \\ a Division of Fluid and Climate Technology, School of Architecture and the Built Environment, KTH Royal Institute of Technology, Stockholm, Sweden \\ ${ }^{\mathrm{b}}$ International Centre for Indoor Environment and Energy, Department of Civil Engineering, Technical University of Denmark, DTU, Copenhagen, Denmark
}

\section{A R T I C L E I N F O}

\section{Article history:}

Received 18 May 2015

Received in revised form

21 September 2015

Accepted 25 September 2015

Available online 30 September 2015

\section{Keywords:}

Low-temperature hydronic heating systems

Energy performance

Thermal environment

Experimental study

Ventilation radiator

Floor heating

\begin{abstract}
A B S T R A C T
Energy consumption, thermal environment and environmental impacts were analytically and experimentally studied for different types of heat emitters. The heat emitters studied were conventional radiator, ventilation radiator, and floor heating with medium-, low-, and very-low-temperature supply, respectively. The ventilation system in the lab room was a mechanical exhaust ventilation system that provided one air change per hour of fresh air through the opening in the external wall with a constant temperature of $5^{\circ} \mathrm{C}$, which is the mean winter temperature in Copenhagen. The parameters studied in the climate chamber were supply and return water temperature from the heat emitters, indoor temperature, and heat emitter surface temperature. Experiments showed that the mean supply water temperature for floor heating was the lowest, i.e. $30^{\circ} \mathrm{C}$, but it was close to the ventilation radiator, i.e. $33^{\circ} \mathrm{C}$. The supply water temperature in all measurements for conventional radiator was significantly higher than ventilation radiator and floor heating; namely, $45^{\circ} \mathrm{C}$. Experimental results indicated that the mean indoor temperature was close to the acceptable level of $22^{\circ} \mathrm{C}$ in all cases. For energy calculations, it was assumed that all heat emitters were connected to a ground-source heat pump. Analytical calculations showed that using ventilation radiator and floor heating instead of conventional radiator resulted in a saving of $17 \%$ and $22 \%$ in heat pump's electricity consumption, respectively. This would reduce the $\mathrm{CO}_{2}$ emission from the building's heating system by $21 \%$ for the floor heating and by $18 \%$ for the ventilation radiator compared to the conventional radiator.
\end{abstract}

(c) 2015 Elsevier B.V. All rights reserved.

\section{Introduction}

The level of water temperature supplied to the heat emitter in buildings plays a major role in primary energy consumption and environmental impacts. As more and more buildings are becoming energy-efficient due to better thermal insulation, less infiltration and more efficient heating and ventilation systems, heat losses from buildings are decreasing. All these changes could be the reasons to reduce the need to supply the heating system with water at temperature as high as previously. As the temperature to the heat emitter decreases, heat losses from the heat production unit and from distribution pipes decrease, and consequently, more renewable and low-quality energy sources can be used [1]. Boerstra et al. [2] defined different supply temperature levels; namely, $55^{\circ} \mathrm{C}$ for medium-, $45^{\circ} \mathrm{C}$ for low-, and $35^{\circ} \mathrm{C}$ for very-low-temperature heat emitters. The main principle of low-temperature heating system

\footnotetext{
* Corresponding author at: Brinellvägen 23, 10044 Stockholm, Sweden.

E-mail address: arefeh.hesaraki@byv.kth.se (A. Hesaraki).
}

is to provide the same thermal comfort as a medium-temperature heating system, while using a lower supply temperature [3]. Supporting a low-temperature heat emitter with a heat pump is thermally efficient. Generally, the thermal efficiency of a heat pump is improved by one to two percent for every degree by which the supply water temperature is reduced [4]. Heat pumps have been recognized for many years as an energy-efficient and sustainable heat source that, by utilizing renewable energy, uses three to four times less electrical energy to deliver the same amount of heat as a direct electrical heater. By 2013, more than half of detached and semi-detached dwellings in Sweden have had heat pumps installed [5]. Therefore, as the number of heat pumps sold in Sweden and Europe increases, there is a growing need to adjust the temperature of heat emitters to this change in order to attain greater efficiency; that is, to use low-temperature heat emitters. In addition, some recent studies have focused on low-temperature district heating, known as the fourth generation of district heating networks [6]. This means that, in the future, the supply water temperature to buildings connected to district heating - that is, more than $90 \%$ of Swedish apartment buildings - will also decrease. Therefore, 


\begin{tabular}{|c|c|}
\hline \multicolumn{2}{|c|}{ Nomenclature } \\
\hline COP & coefficient of performance \\
\hline$D_{h}$ & degree hours per year, ${ }^{\circ} \mathrm{C}$ h year ${ }^{-1}$ \\
\hline E & energy demand by building, kWh year $^{-1}$ \\
\hline$E_{e l}$ & $\begin{array}{l}\text { electrical energy consumption by heat pump, } \\
\text { kWhyear }^{-1}\end{array}$ \\
\hline $\begin{array}{l}g_{e l} \\
\text { GSHP }\end{array}$ & $\begin{array}{l}\mathrm{CO}_{2} \text { emission factor for electricity, } \mathrm{kg}_{\mathrm{CO}_{2}} \mathrm{kWh}^{-1} \\
\text { ground-source heat pump }\end{array}$ \\
\hline$h_{g l, s u r f}$ & $\begin{array}{l}\text { total heat transfer coefficient at inner glazing sur- } \\
\text { face of windows, } \mathrm{W} \mathrm{m}^{-2} \mathrm{~K}^{-1}\end{array}$ \\
\hline$n$ & number of measurements \\
\hline \multicolumn{2}{|c|}{$\begin{array}{l}P_{\text {passive,indirect passive (indirect) internal and external heat }} \\
\text { gains, } \mathrm{W}\end{array}$} \\
\hline Qtot & specific heat loss, $\mathrm{W}^{\circ} \mathrm{C}^{-1}$ \\
\hline SD & standard deviation \\
\hline$U_{\text {wall }}$ & heat transfer coefficient of wall, $\mathrm{W} \mathrm{m}^{-2} \mathrm{~K}^{-1}$ \\
\hline$U_{\text {window }}$ & heat transfer coefficient of windows, $\mathrm{W} \mathrm{m}^{-2} \mathrm{~K}^{-1}$ \\
\hline$x_{i}$ & measured parameter \\
\hline$x_{m}$ & mean value of measured data \\
\hline$\theta_{\text {base }}$ & $\begin{array}{l}\text { base temperature at which the heat loss from build- } \\
\text { ing is equal to heat generated by active heating } \\
\text { system, }{ }^{\circ} \mathrm{C}\end{array}$ \\
\hline$\theta_{\text {gl,surf }}$ & window’s surface temperature, ${ }^{\circ} \mathrm{C}$ \\
\hline & indoor temperature, ${ }^{\circ} \mathrm{C}$ \\
\hline & outdoor temperature, ${ }^{\circ} \mathrm{C}$ \\
\hline
\end{tabular}

there is also a need to renovate existing apartment buildings to be adapted for a lower supply water temperature. A reduced return temperature level also favors district heating networks in terms of higher efficiency of heat generation plants, heat pumps, and solar collectors. Furthermore, with a requirement for lower supply temperature level surplus and waste heat could be used as an efficient heat source in a district heating system.

Using a low-temperature heating system is also more sustainable due to a reduction in the generation of carbon dioxide. For every degree reduction of the supply temperature in a heating system, the carbon dioxide emission decreases by $1.6 \%$ [4]. Ploskic [4] showed that by using a water supply temperature of $40^{\circ} \mathrm{C}$ instead of $55^{\circ} \mathrm{C}$, heat pump efficiency would increase by $25 \%$ and the carbon dioxide emissions would decrease by $24 \%$.

In some investigations [7-9], low-temperature panel heating had better indoor air quality than a high-temperature heating system. This was due to the correlation between the temperature of heating surface and particle deposition and also the mite population. In addition, thermal comfort increases by a greater share of radiant heat transfer and lower vertical temperature gradient in a room with low-temperature panel heating, which makes it possible to reduce the indoor temperature. This would also decrease ventilation heat losses. Experimental investigations by Zhao et al. [10] showed better thermal environment and energy savings with low-temperature heating and high-temperature cooling compared to the jet ventilation system in China's International Airport. Primary annual energy calculation based on Energy Performance of Buildings Directive (EPBD) by Olesen and Carli [11] showed that a low-temperature heating system connected to a ground-source heat pump has better overall energy performance than a conventional radiator connected to a boiler or an air to water heat pump. Hasan et al. [12] studied the performance of low-temperature heating systems in terms of energy consumption and thermal comfort. Their results showed that although the supply temperature decreased to $45^{\circ} \mathrm{C}$ in a conventional radiator, the indoor temperature never dropped below $20^{\circ} \mathrm{C}$. This was due to an oversized conventional radiator for a well-insulated building.

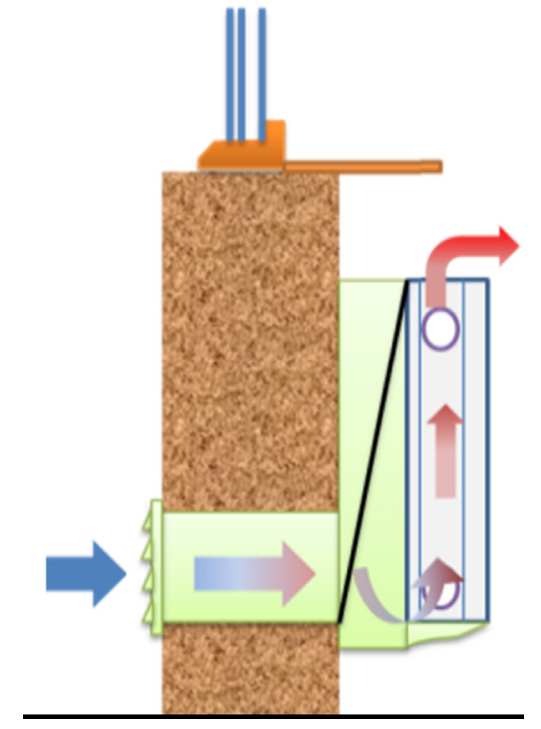

Fig. 1. Schematic of ventilation radiator; that is, the combination of supply ventilation with radiator to preheat the cold supply air and increase the efficiency of the radiator.

Maivel and Kurnitski [13] investigated the distribution and emission losses for a low-temperature heating system compared to a high-temperature heating system installed in different building types located in a cold and Central European climate. Their results showed that depending on the building type, climate condition and heating period, using high-temperature heating with $70^{\circ} \mathrm{C}$ water supply temperature has $4-40 \%$ higher losses compared to low-temperature heating system with $40^{\circ} \mathrm{C}$ water supply temperature. Nagy et al. [14] developed a model to investigate the influence of retrofit measures to the supply water temperature. Their results showed that the supply water temperature to the existing building without any retrofit measures can be decreased by $10^{\circ} \mathrm{C}$; that is, from 55 to $45^{\circ} \mathrm{C}$, without sacrificing thermal comfort. In addition, they showed that improving the building's insulation would allow to decrease the supply temperature to $40{ }^{\circ} \mathrm{C}$ and to save energy by $60 \%$ compared to the reference case.

There are different types of low-temperature room heaters in which the large surface area or improved forced convection makes it possible to reduce the supply water temperature without sacrificing the heat output. Examples include panel heating such as floor, ceiling or wall heating, or forced-convection radiator such as ventilation radiators [15], or add-on fan radiators [16]. In a ventilation radiator, the ventilation supply is placed behind the radiator; see Fig. 1. This combination increases the forced convection heat transfer and makes it possible to pre-heat the supply air before it enters the room. An experimental investigation [15] showed that an efficient ventilation radiator produced twice as much heat output as a conventional radiator under the same conditions. This was due to the high convective heat transfer by combining it with incoming air, and also the large temperature difference between cold incoming air and the heat emitting surface.

In the add-on fan radiator, fans are placed below the radiator panels to boost the convection heat transfer. A previous study [16] showed that having five fans below the radiator increases the heat output to almost twice that of a conventional radiator. This was due to increasing the convection heat transfer along the radiator surfaces. Added fans below the radiator consumed very small amounts of electricity, that is, the ratio of electricity consumption by the fan to increasing the heat output of the radiator was between one and two percent. 
For floor heating, the temperature difference between supply and return is decreased due to the preferred homogenous temperature along the floor. This would require a higher flow rate, followed by increasing auxiliary hydraulic pressure loss and work for the circulation pump [11] compared to a hydronic radiator system. In addition to higher circulation pump work, higher primary energy consumption in floor heating could be due to high heat loss to the ground because the heating system is not completely interior and is embedded in the envelope [17]. However, this problem could be solved by adding more insulation under the floors. Sarbu and Sebarchievici [18] investigated thermal comfort, energy savings, environmental impacts, and economic performance of low-temperature heating systems, including floor heating, wall heating, ceiling heating, and a combination of floor and ceiling heating. Their study showed that floor-ceiling heating provided the best performance in terms of energy consumption, environmental impacts, and operating cost.

Statistical data showed that an average Swedish detached and semi-detached house built between 2001 and 2012 had annual energy consumption of $84 \mathrm{kWh} \mathrm{m}^{-2}$ for producing and transporting heat to cover space heating and domestic hot water [19]. Energy measurements by Hesaraki and Holmberg [20] for five semi-detached houses built in 2011 equipped with low-, and verylow-temperature heat emitters, including floor heating on the first floor and ventilation radiator on the second and third floors, showed an average annual energy requirement of $48 \mathrm{kWh} \mathrm{m}^{-2}$ for space heating and domestic hot water. This consumption was $43 \%$ less than that in an average detached and semi-detached house built between 2001 and 2012 .

Previous studies have focused on the energy consumption of low-temperature heat emitters, leaving the question of how much the actual savings are compared to conventional radiator under the same conditions still to be addressed. However, the laboratory measurements, simulations and field tests have indicated that lowand very-low-temperature heat emitters could be an energy-saving alternative compared to conventional radiators $[15,20]$. To evaluate and compare the performance of low- and very-low-temperature heating systems, including ventilation radiators and floor heating, with conventional radiators, laboratory measurements were conducted. Afterwards, a detailed comparison of energy performance, thermal environment and environmental impacts in conventional radiator, ventilation radiator, and floor heating was made.

\section{Methodology}

The methodology consists of evaluating a medium-, low- and very-low-temperature heat emitters in a climate chamber test facility at Technical University of Denmark (DTU).

\subsection{Climate chamber description}

The geometrical dimensions of climate chamber were $4.0 \mathrm{~m} \times 4.2 \mathrm{~m} \times 2.7 \mathrm{~m}$; see Fig. 2 . The simulated room there represented a living room where two persons are at home during the evening. The room was simulated with one external wall, including a cold window $(4.0 \mathrm{~m} \times 1.6 \mathrm{~m})$, and three internal adiabatic walls with an adiabatic floor and ceiling. The $U$ value of windows and wall were considered to be 2.10 and $0.25\left(\mathrm{~W} \mathrm{~m}^{-2} \mathrm{~K}^{-1}\right)$, respectively, corresponding to an average multi-family building built between 1976 and 2005 [21].

Two seated and relaxed persons, two laptops and two lamps were used as internal heat source generators, creating a total of $204 \mathrm{~W}$ of heat. The ventilation rate was set to 1 air change per hour, corresponding to $12.61 \mathrm{~s}^{-1}$ with an inlet constant temperature of approximately $5^{\circ} \mathrm{C}$, which is the average winter temperature

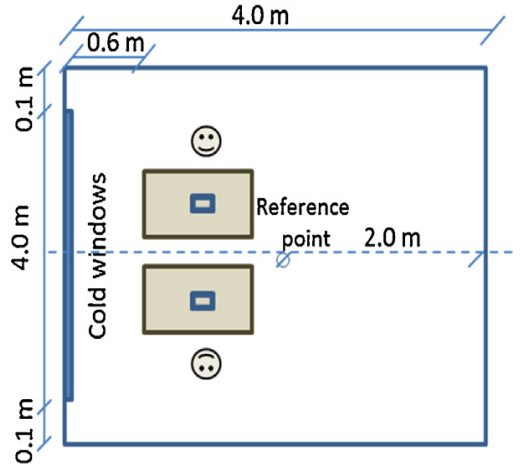

Fig. 2. Climate chamber study at DTU University.

in Copenhagen occurring $80 \%$ of heating season. Furthermore, as northern climate countries lack solar radiation during winter days, the influence of external heat gains from solar energy is negligible, and therefore was not considered in this study. In addition, since the climate chamber was not very tight, $10 \%$ leakage was assumed when calculating total heat losses. The outdoor temperature of $5{ }^{\circ} \mathrm{C}$ was used to calculate temperature of the cold windows; see Eq. (1). In Eq. (1), for the total heat transfer coefficient at the inner glazing surface, the mean value of $7.6 \mathrm{~W} \mathrm{~m}^{-2} \mathrm{~K}^{-1}$ was used [22].

$\theta_{\text {gl,surf }}=\theta_{i}-\frac{U_{\text {windows }}}{h_{\text {gl,surf }}}\left(\theta_{i}-\theta_{0}\right)$

where $\theta_{i}$ and $\theta_{o}$ are the indoor and outdoor temperatures $\left({ }^{\circ} \mathrm{C}\right)$, respectively, $U_{\text {window }}$ and $h_{\text {gl,surf }}$ are the heat transfer coefficient of windows and the inner glazing surface of windows $\left(\mathrm{W} \mathrm{m}^{-2} \mathrm{~K}^{-1}\right)$, respectively.

Heat losses and passive heat gains in the room caused a heat demand of $20 \mathrm{~W} \mathrm{~m}^{-2}$ to be covered by an active heating source. The boundary conditions for measurements are shown in Table 1. Three types of heat emitters were used: conventional radiator, ventilation radiator, and floor heating; see Fig. 3. For floor heating and conventional radiator, a fresh air supply diffuser was placed above the window. In case of ventilation radiator, cold ventilation air was preheated by passing through the radiator's panels before entering the room. In order to simulate a living room, the exhaust air duct was placed at low level in the climate chamber. This was similar to the case in which the air was exhausted from below the door in the living room; as there is no exhaust device in this room.

All measurements were made in a steady state condition; that is, constant heat losses in terms of ventilation temperature, ventilation flow rate, and windows' temperature, and constant internal heat gains. Steady state condition was reached after three hours for each measurement. Measurements were conducted for approximately $45 \mathrm{~h}$ for each type of heat emitter.

\subsection{Thermal environment and heat output of heat emitters}

To measure the water, air, and surface temperatures, plasticcoated paper probes with a sensor made of a film thermistor on an aluminum oxide substrate with accuracy of $\pm 0.3^{\circ} \mathrm{C}$ were used. To avoid radiant heat exchange, a small piece of thermal insulation together with aluminum foil to shield the sensors was used. The mean indoor temperature was measured in the center of the room at a height of $1.1 \mathrm{~m}$, representing the breathing zone of a seated person. In addition, the surface temperatures of windows and heat emitter were measured at different points. To measure the temperature of ventilation supply the sensor was placed on the supply air diffuser. Furthermore, the temperatures of inlet and outlet water of the heat emitters were monitored inside the pipes right before and after passing through the heat emitter, respectively. 
Table 1

Boundary conditions for experiments in the DTU climate chamber.

\begin{tabular}{|c|c|c|c|c|c|}
\hline \multicolumn{2}{|l|}{ Transmission loss } & \multicolumn{2}{|l|}{ Ventilation loss } & \multicolumn{2}{|l|}{ Heat gains } \\
\hline$U_{\text {external wall }}, \mathrm{W} \mathrm{m}^{-2} \mathrm{~K}^{-1}$ & 0.25 & Ventilation type & Mechanical exhaust & Passive heat sources & 2 persons, 2 lamps, 2 laptops \\
\hline External wall area, $\mathrm{m}^{2}$ & 3.26 & & & & \\
\hline$U_{\text {window }}, \mathrm{W} \mathrm{m}^{-2} \mathrm{~K}^{-1}$ & 2.10 & Ventilation rate, $1 \mathrm{~s}^{-1}$ & 12.6 & Active heat sources & Floor heating \\
\hline Window area, $\mathrm{m}^{2}$ & 6.40 & Leakage rate, $1 \mathrm{~s}^{-1}$ & 1.26 & & Ventilation radiator, \\
\hline Window temperature, ${ }^{\circ} \mathrm{C}$ & 16.6 & Ventilation temperature, ${ }^{\circ} \mathrm{C}$ & 5.0 & & Conventional radiator \\
\hline Outdoor temperature, ${ }^{\circ} \mathrm{C}$ & 5.0 & & & & \\
\hline
\end{tabular}
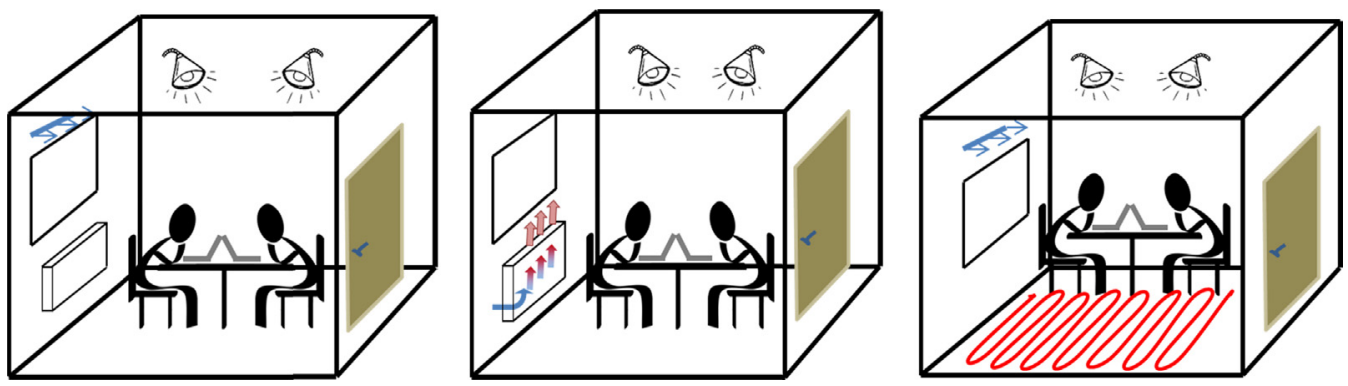

Fig. 3. Conventional radiator (left), ventilation radiator (middle) and floor heating (right) used for investigation.

The heat output of each heat emitter was calculated based on the mean room temperature, the ventilation supply temperature, the water supply, and the return temperature using a calculation code given by the manufactures. Heat output of radiators and floor heating given in manufacturer's heat emission data were in accordance with European Norms of EN 442 and EN 1246, respectively $[23,24]$. The maximum deviation of $\pm 2 \%$ in heat output compared to other certificated laboratories [25] should be kept for holding the license for testing, according to the EN. Therefore, the thermal power given by the manufacturer's data is reliable with high precision.

\subsection{Uncertainty analysis}

To analyze the uncertainty integrated in the measurements, the standard deviation (SD) of variables representing statistical error was considered. Since the entire population were taken, population standard deviation was used; see Eq. (2).

$\mathrm{SD}=\sqrt{\frac{1}{n} \sum_{i=1}^{n}\left(x_{i}-x_{m}\right)^{2}}$

where $n$ is the number of measurements, $x_{m}$ is mean value of measured data, and $x_{i}$ is measured data.

\subsection{Energy consumption and environmental impacts of heat emitters}

The degree-hours $\left(D_{h}\right)$ method was used to calculate energy demand for active heating; see Eq. (3). The degree hours mainly depend on the building location and the base temperature.

$E=Q_{\text {tot }} \cdot D_{h}$

where $Q_{\text {tot }}$ is the specific heat loss $\left(\mathrm{W}^{\circ} \mathrm{C}^{-1}\right)$ and $D_{h}$ is degree hours per year $\left({ }^{\circ} \mathrm{Ch}\right.$ year $\left.{ }^{-1}\right)$.

The base temperature is defined as the outside temperature above which the building needs no active heating. In this temperature, the heat loss from the building is equal to the heat generated by the active heating system. The difference between the base temperature and the desired indoor temperature is covered by internal and external heat gains from sources such as occupants, equipment, lighting, and solar energy; this is called passive or indirect heat $\left(P_{\text {passive,indirect }}\right)$. For the climate chamber under study, the passive or indirect heat was calculated to be $204 \mathrm{~W}$ based on two sitting people, each generating $80 \mathrm{~W}$, and two lamps and two laptops, generating $44 \mathrm{~W}$. Using Eq. (4), the base temperature for the studied room was calculated as $15^{\circ} \mathrm{C}$; that is, specific heat loss of $31.4 \mathrm{~W}^{\circ} \mathrm{C}^{-1}$ and an indoor temperature of $22^{\circ} \mathrm{C}$. The average annual degree hours during 2010-2014 for Copenhagen, with annual mean temperature of $8.6^{\circ} \mathrm{C}$ and base temperature of $15^{\circ} \mathrm{C}$, was $63,912{ }^{\circ} \mathrm{Ch}_{\text {year }}^{-1}[26]$.

$\theta_{\text {base }}=\theta_{i}-\frac{P_{\text {Passive, indirect }}}{Q_{\text {tot }}}$

where $\theta_{\text {base }}$ and $\theta_{i}$ are base and indoor temperatures $\left({ }^{\circ} \mathrm{C}\right)$, respectively, $P_{\text {passive, indirect }}$ is heat contribution from internal and external heat gains $(\mathrm{W})$.

In order to analyze the data in terms of energy consumption, it was assumed that the heat emitters were connected to a ground-source heat pump (GSHP). Therefore, to calculate energy consumption, the total energy demand was divided by the coefficient of performance (COP) of heat pump, see Eq. (5). To find the mean annual COP of the heat pump, a commercial program called Vitocalc 2010, developed by Viessmann, was used [27]. The input data to the Vitocalc program to calculate the COP are the type of the heat pump, climate condition (design outdoor temperature, and mean annual temperature), building properties (heat demand, desired indoor temperature), heat sink temperature (supply and return temperature of the heat emitter), efficiency of the compressor, and heat source temperature. In case of GSHP, the ground properties of previous experimental study [28] at Technical University of Denmark were used. In this project the soil was determined as $4-5 \mathrm{~m}$ thick layer of clay with water saturated sand below this layer. In this condition, the thermal conductivity and the thermal diffusivity of ground were determined as $0.90-1.15 \mathrm{~W} \mathrm{~m}^{-1} \mathrm{~K}^{-1}$ and $5.4 \times 10^{-7}-10.0 \times 10^{-7} \mathrm{~m}^{2} \mathrm{~s}^{-1}$, respectively. As a heat exchanger, one borehole fitted by a single U-pipe with a diameter of $40 \mathrm{~mm}$ was considered in Vitocalc software.

$E_{e l}=\frac{E}{\mathrm{COP}}$

With respect to environmental impacts, the $\mathrm{CO}_{2}$ emissions from heating systems were calculated based on heat pump's electrical energy consumption $\left(E_{e l}\right)$ and specific $\mathrm{CO}_{2}$ emission factor for 
Conventional radiator

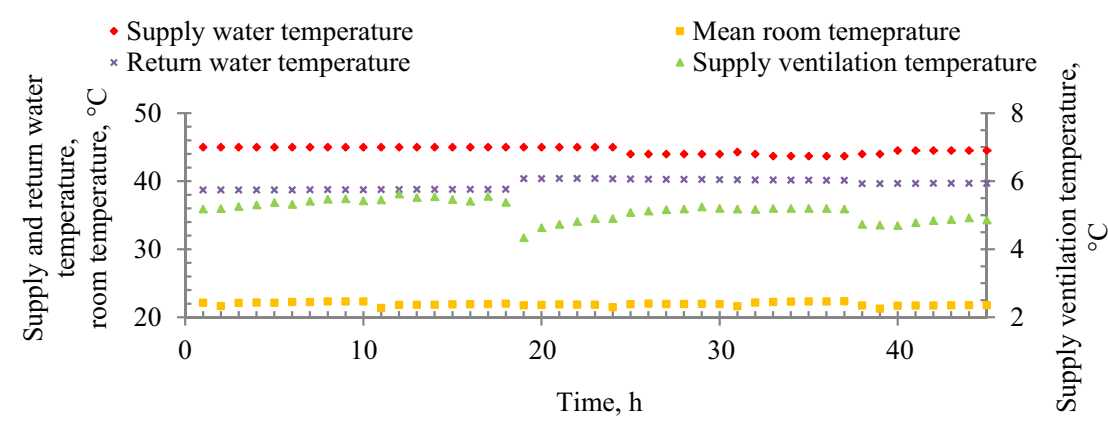

Fig. 4. Temperature measurements for conventional radiator.
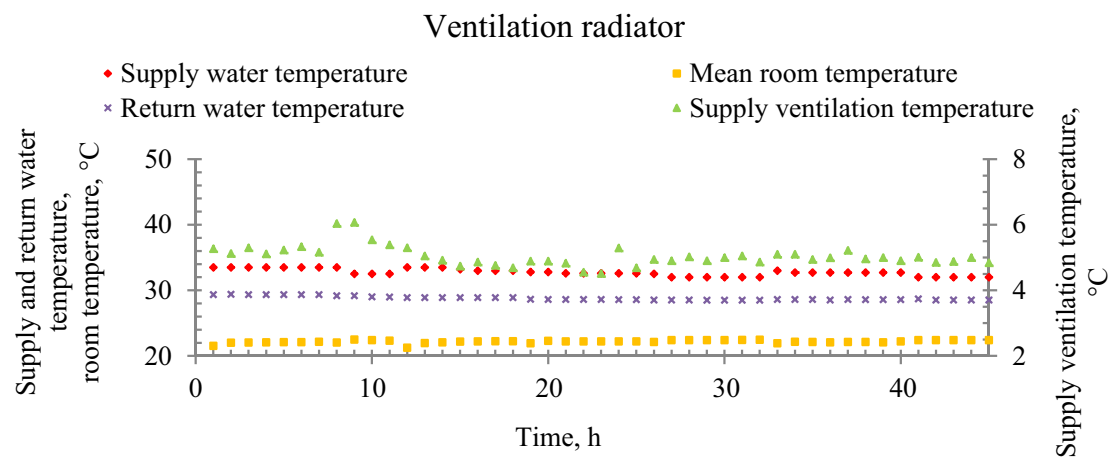

Fig. 5. Temperature measurements for ventilation radiator.

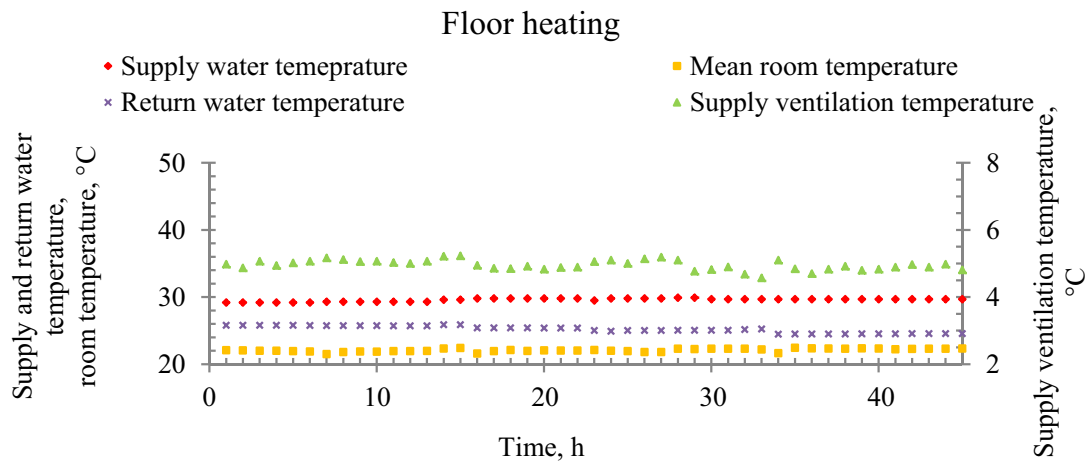

Fig. 6. Temperature measurements for floor heating.

electricity $\left(g_{e l}\right)$, which is $0.041 \mathrm{~kg}_{\mathrm{CO}_{2}} \mathrm{kWh}^{-1}$ in Sweden [29]; see Eq. (6).

$\mathrm{CO}_{2}=g_{e l} E_{e l}$

\section{Results and discussion}

Figs. 4-6 show the supply and return temperature for the heat emitters, the supply temperature for ventilation, and the mean room temperature at the reference point for the conventional radiator, ventilation radiator, and floor heating, respectively. Due to the high mass flow rate to all types of heat emitter, the mean temperature difference between return and supply was between 4 and 5 $\left({ }^{\circ} \mathrm{C}\right)$. The mean supply water temperature for floor heating was the lowest, i.e. $30^{\circ} \mathrm{C}$, but it was close to the ventilation radiator, i.e. $33^{\circ} \mathrm{C}$. The supply water temperature in all measurements for conventional radiator was significantly higher than ventilation radiator and floor heating; namely, $45^{\circ} \mathrm{C}$.
Table 2 shows the results of the thermal environment for each case. As can be seen, the mean room temperature at the reference point was $22.1^{\circ} \mathrm{C}$ for all cases when the supply ventilation temperature and the cold window's temperature were approximately 5.0 and $16.6\left({ }^{\circ} \mathrm{C}\right)$, respectively. The mean surface temperature of the ventilation radiator was $11.2{ }^{\circ} \mathrm{C}$ less than the conventional radiator. This was due to the lower temperature in supply water, and also cold ventilation air blowing between radiator's panels. In the case of floor heating, the mean temperature of the floor surface was $23.2^{\circ} \mathrm{C}$, which according to the ASHRAE 55-2010 standard is within the acceptable range. Using degree-hours method, the annual energy demand was calculated as $119 \mathrm{kWh} \mathrm{m}^{-2}$; that is, multiplying the specific heat loss of $31.4 \mathrm{~W}^{\circ} \mathrm{C}^{-1}$ by the degree hours of $63,912^{\circ} \mathrm{C}$ hear ${ }^{-1}$. In addition, energy consumption and $\mathrm{CO}_{2}$ emissions were calculated as electrical energy consumed by a ground-source heat pump; see Table 3 . As can be seen in Table 3, energy consumption and $\mathrm{CO}_{2}$ emissions from floor heating were lower compared to the other systems. Energy was reduced by 17 and 22 (\%), when using ventilation radiator and 
Table 2

Thermal environment measurements for each type of heat emitters (all units are in ${ }^{\circ} \mathrm{C}$ ).

\begin{tabular}{|c|c|c|c|c|c|}
\hline Type of heat emitter & $\begin{array}{l}\text { Mean ventilation } \\
\text { temperature }\end{array}$ & $\begin{array}{l}\text { Mean room } \\
\text { temperature }\end{array}$ & $\begin{array}{l}\text { Mean water } \\
\text { temperature } \\
\text { (supply/return) }\end{array}$ & $\begin{array}{l}\text { Mean window } \\
\text { surface } \\
\text { temperature }\end{array}$ & $\begin{array}{l}\text { Mean surface } \\
\text { temperature of } \\
\text { heat emitter }\end{array}$ \\
\hline Floor heating & 5.0 & 22.1 & $30.0 / 25.0$ & 16.5 & 23.2 \\
\hline Ventilation radiator & 5.0 & 22.2 & $33.0 / 29.0$ & 16.7 & 26.8 \\
\hline Conventional radiator & 5.1 & 21.9 & $45.0 / 40.0$ & 16.5 & 38.0 \\
\hline
\end{tabular}

Table 3

Energy performance and $\mathrm{CO}_{2}$ emissions from each type of heat emitters.

\begin{tabular}{|c|c|c|c|c|}
\hline Type of heat emitters & COP of GSHP & Mean heat output, $\mathrm{W}$ & $\begin{array}{l}\text { Annual energy consumption, } \\
\mathrm{kWh} \mathrm{m}^{-2} \text { (saving, \%) }\end{array}$ & $\begin{array}{l}\text { Annual } \mathrm{CO}_{2} \\
\text { emissions, kg } \\
\text { (saving, \%) }\end{array}$ \\
\hline Floor heating & 4.5 & 336 & $27(22)$ & $18.6(21)$ \\
\hline Ventilation radiator & 4.2 & 350 & $28(17)$ & $19.3(18)$ \\
\hline Conventional radiator & 3.5 & 329 & $34(-)$ & $23.4(-)$ \\
\hline
\end{tabular}

Table 4

Standard deviation of measured parameters.

\begin{tabular}{|c|c|c|c|c|}
\hline Standard deviation & Water temperature & Air temperature & Surface temperature & Heat output \\
\hline Floor heating & $1 \%\left(0.2^{\circ} \mathrm{C}\right)$ & $1 \%\left(0.2^{\circ} \mathrm{C}\right)$ & $1 \%\left(0.1^{\circ} \mathrm{C}\right)$ & $6 \%(21 \mathrm{~W})$ \\
\hline Ventilation radiator & $1 \%\left(0.3^{\circ} \mathrm{C}\right)$ & $1 \%\left(0.2^{\circ} \mathrm{C}\right)$ & $1 \%\left(0.2^{\circ} \mathrm{C}\right)$ & $4 \%(13 W)$ \\
\hline Conventional radiator & $1 \%\left(0.3^{\circ} \mathrm{C}\right)$ & $1 \%\left(0.2^{\circ} \mathrm{C}\right)$ & $2 \%\left(0.3^{\circ} \mathrm{C}\right)$ & $2 \%(8 W)$ \\
\hline
\end{tabular}

floor heating, respectively, compared to conventional radiator. In addition, $\mathrm{CO}_{2}$ emission savings were 18 and 21 (\%) for ventilation radiator and floor heating, respectively, compared to conventional radiator.

\subsection{Uncertainty analysis of laboratory measurements}

Calculations of uncertainty analysis showed that the largest standard deviation was for the heat output of the floor heating; namely $6 \%$, and the smallest deviation of $1 \%$ was for the surface, air and water temperature; see Table 4 . In addition, it should be noted that as the average winter condition; that is, $80 \%$ of heating season, was considered, all results of annual energy and environmental savings would be also affected by the same validity of $80 \%$.

\section{Conclusion}

As shown by this study, in order to achieve greater efficiency and savings in energy and environmental impacts in the heating system of buildings there is a need to decrease supply temperature to the heating system. In terms of energy savings, $12-15^{\circ} \mathrm{C}$ temperature reduction in supply water temperature of low-, and very-lowtemperature heat emitters saved energy by $17-22 \%$ compared to a medium-temperature heat emitter. These savings were calculated in terms of electricity consumption by a ground-source heat pump. With respect to environmental impacts, this temperature reduction caused reducing the $\mathrm{CO}_{2}$ emissions by $18-21 \%$ in low-, and very-low-temperature heat emitter compared to a mediumtemperature heat emitter. Results showed that all heat emitters provided an acceptable level of thermal comfort in the room with $22{ }^{\circ} \mathrm{C}$ at the reference point. Therefore, providing the same thermal comfort, the lower supply temperature to the heat emitters caused higher efficiency and sustainability in the heating system. In low-temperature heating systems, losses from production units, distribution pipes, and heat emitters are reduced. In addition, renewable-based heat sources, such as heat pumps, and fourthgeneration district heating networks, attain higher efficiency and sustainability when being connected to low-temperature heat emitters.

\section{Acknowledgements}

The authors would like to acknowledge Professor Bjarne W. Olesen, Angela Simone, and Quan Jin for helping with measurements, and Mikko Iivonen from Rettig for ordering the radiators. In addition, we are grateful to the Swedish Energy Agency (Energimyndigheten), the Swedish Centre for Innovation and Quality in the Built Environment (IQ Samhällsbyggnad), and SBUF, the Development Fund of the Swedish Construction Industry for financial support.

\section{References}

[1] M. Banjac, B. Vasiljević, M. Gojak, Low-temperature hydronic heating system with radiators and geothermal ground source heat pump, Fac. Mech. Eng. Trans. 35 (2007) 129-134.

[2] A. Boersta, P.O. Veld, H. Eijdems, The health, safety and comfort advantages of low-temperature heating system: a literature review, in: Proceedings of the 6 th International Conference on Healthy Buildings, Espoo, Finland, August, 2000.

[3] M. Bojic, D. Cvetkovic, D. Marjanovic, M. Blagojevic, Z. Djordjevic, Performances of low temperature radiant heating systems, Energy Build. 61 (2013) 233-238.

[4] A. Ploskic, Technical Solution for Low-temperature Heat Emission in Buildings (Ph.D. thesis in Civil and Architectural Engineering), KTH Royal Institute of Technology, Stockholm, Sweden, 2013.

[5] Energy Statistics for One- and Two-dwelling Buildings in 2013, Swedish Energy Agency, EN0102BR1401, 2014.

[6] H. Lund, S. Werner, R. Wiltshire, S. Svendsen, J.E. Thorsen, F. Hvelplund, B.V. Mathiesen, 4th-Generation District Heating (4GDH): integrating smart thermal grids into future sustainable energy systems, Energy 68 (2014) 1-11.

[7] E. Sammaljarvi, Heating, indoor dusts, stuffiness and room space electricity as health and well-being risks, in: Proceedings of Healthy Buildings, 1998, p. 697.

[8] P. Lengweiler, P.V. Nielsen, A. Moser, et al., Deposition and resuspension of particles, in: Proceedings Healthy Buildings 97, vol. 1, 1997, p. 501.

[9] M. Schata, J.H. Elixman, W. Jorde, Evidence of heating systems in controlling house-dust mites and moulds in the indoor environment, in: Proceedings Indoor Air 90, vol. 4, 1990, p. 577.

[10] K. Zhao, X.-H. Liu, Y. Jiang, On-site measured performance of a radiant floor cooling/heating system in Xi'an Xianyang International Airport, Sol. Energy 108 (2014) 274-286

[11] B.W. Olesen, M.D. Carli, Calculation of the yearly energy performance of heating systems based on the European Building Energy Directive and related CEN standards, Energy Build. 43 (2011) 1040-1050.

[12] A. Hasan, J. Kurnitski, K. Jokiranta, A combined low-temperature wate heating system consisting of radiators and floor heating, Energy Build. 41 (2009) 470-479. 
[13] M. Maivel, J. Kurnitski, Low temperature radiator heating distribution and emission efficiency in residential buildings, Energy Build. 69 (2014) 224-236.

[14] Z. Nagy, D. Rossi, C. Hersberger, S.D. Irigoyen, C. Miller, A. Schlueter, Balancing envelope and heating system parameters for zero emissions retrofit using building sensor data, Appl. Energy 131 (2014) 56-66.

[15] J.A. Myhren, Potential of Ventilation Radiators: Performance Evaluation by Numerical, Analytical and Experimental Investigations (Doctoral thesis in Civil and Architectural Engineering), KTH Royal Institute of Technology, Stockholm, Sweden, 2011.

[16] P.O. Johansson, J. Wollerstrand, Improved temperature performance of radiator heating system connected to district heating by using add-on-fan blowers, in: Proceedings of the 12th International Symposium on District Heating and Cooling, Tallinn, Estonia, 2010.

[17] A. Hesaraki, S. Holmberg, Demand-controlled ventilation in new residential buildings: consequences on indoor air quality and energy savings, Indoor Built Environ. 24 (2015) 162-173.

[18] I. Sarbu, C. Sebarchievici, A study of performances of low-temperature heating systems, Energy Effic. 8 (2015) 609-627.

[19] Energy Statistics for One- and Two-dwelling Buildings in 2013. Swedish Energy Agency, ES 2014:05 ISSN:654-7543.

[20] A. Hesaraki, S. Holmberg, Energy performance of low-temperature heating systems in five new-built Swedish dwellings: a case study using simulations and on-site measurements, Build. Environ. 64 (2013) 85-93.
[21] Energy Use in Buildings - Technical Properties and Calculations - Results From the Project BETSI, National Board of Housing, Building and Planning, 2010, ISBN 978-91-86559-83-0 (in Swedish).

[22] A. Ploskic, S. Holmberg, Heat emission from thermal skirting boards, Build Environ. 45 (2010) 1123-1133.

[23] Floor Heating Heat Output Calculator, Manufacturer's Data. In accordance with EN 1246. Available from: http://www.purmo.com/de/produkte/ flaechenheizung/planung-und-montage-planungsgrundlagenwaermeleistungen.htm (in German).

[24] Radiator Heat Output Calculator. Manufacturer's Data. In accordance with EN 442. Available from: http://www.purmo.com/se/ladda-hem-filer/ effektsimulering.htm (in Swedish).

[25] TÜV Rheinland, DIN CERTCO, Certification Scheme DIN-Geprüft, Radiators and Convectors according to DIN EN 442, August, 2008, pp. 1-27.

[26] BizEE Software Ltd. - Business Energy Efficiency Software. Available from: http://www.degreedays.net/.

[27] Vitocalc, Version 1.0, Viessmann Värmeteknik AB, 2005 (in Swedish).

[28] K. Hansen, P. Hansen, Seasonal Heat Storage in Underground Warm Water Stores (Construction and Testing of a $500 \mathrm{~m}^{3}$ Store), Technical University of Denmark, 1981.

[29] IPCC/TEAP Special Report: Safeguarding the Ozone Layer and the Global Climate System: Issues Related to Hydrofluorocarbons and Perfluorocarbons. 